\section{'Charleston Blackeye', a Root-knot Nematode Resistant, Blackeye-type Southernpea for the Production of Fresh-shell Peas}

\author{
Richard L. Fery and Judy A. Thies \\ U. S. Department of Agriculture, Agricultural Research Service, U.S. Vegetable \\ Laboratory, 2700 Savannah Highway, Charleston, SC 29414-5334
}

Additional index words. Vigna unguiculata, cowpea, Meloidogyne, nematode resistance, vegetable breeding

'Charleston Blackeye' is a new southernpea [Vigna unguiculata (L.) Walp.] released by the U.S. Dept. of Agriculture, Agricultural Research Service. 'Charleston Blackeye' was developed for use by both home and market gardeners for the production of traditional, fresh-shell, blackeye-type peas. The new cultivar is highly resistant to root-knotnematodes and is especially adapted for production in the southeastern United States.

\section{Origin}

'Charleston Blackeye' is the product of a pedigree-type breeding program initiated in 1988. The parental lines are US-481 and Au 84G-328. US-481 is the experimental designation of a root-knot nematode (Meloidogyne spp.) resistant, blackeye-type breeding line that was released as 'Bettergro Blackeye' in 1991 (Fery and Dukes, 1993). Au 84-G-328 is a green testa, root-knot nematode susceptible, pinkeye-type breeding line developed by researchers at $\mathrm{Au}-$ burn University. Following the hybridization, intense selection pressure was applied in the $\mathrm{F}_{2}$ through $\mathrm{F}_{8}$ generations for root-knot nematode resistance and superior horticultural characteristics. 'Charleston Blackeye' originated from a bulked $\mathrm{F}_{8}$ population grown in 1996.

\section{Description}

'Charleston Blackeye' has an upright plant habit. The new cultivar is more resistant to lodging than 'Bettergro Blackeye'. The leaf color is a medium green; the leaf surface is blistered and glossy. There is slight to intermediate purple pigmentation on the stems and branches; the petioles exhibit moderate pigmentation at the base and tip; and the peduncles are predominately green colored, but with a tendency for some pigmentation at the base and tip and some intermediate pigmentation on the shaft. Flower color is predominately white; there is slight pigmentation (violet) on the upper front and back margins of the standard and the upper front margin of the wing, moderate pigmenta-

Received for publication 10 Dec. 2005. Accepted for publication 23 Jan. 2006. The technical assistance of Floyd P. Maguire and Sharon Buckner is gratefully acknowledged. tion on the back of the wing, and the base of the standard is yellow. Pods are borne in a scattered fashion at foliage level. Fresh-shell maturity stage pods are attached to the peduncles in a pendant manner, and each peduncle typically produces two pods.

A typical fresh-shell stage pod is an attractive yellow color, $24 \mathrm{~cm}$ long, straight to slightly curved, exhibits only slight constrictions between peas, and contains about 15 peas. Immature pods (snap stage) exhibit a dark green color and a slight purple pigmentation at the tip. Dry pods exhibit a light straw color (Fig. 1). Fresh peas exhibit a primary cream color, have a kidney shape and a small black eye, and weigh 36 g per 100 peas. Dry peas have a rough seed coat.

Replicated dry-pod-harvest field studies were conducted at Charleston, South Carolina,

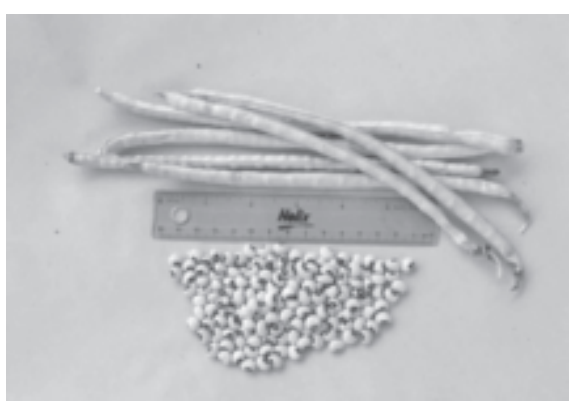

Fig. 1. Dry pods and peas of 'Charleston Blackeye' southernpea.

Table 1. Number of days to harvest, weight per 100 dry peas, and dry pea yield for 'Charleston Blackeye' and 'Green Dixie Blackeye' southernpeas grown in spring trials, Charleston, S.C., 2001-02."

\begin{tabular}{|c|c|c|c|}
\hline Cultivar & $\begin{array}{c}\text { Days to } \\
\text { harvest } \\
\text { (no.) }\end{array}$ & $\begin{array}{c}\mathrm{Wt} / 100 \\
\text { dry peas } \\
(\mathrm{g})\end{array}$ & $\begin{array}{c}\text { Dry pea } \\
\text { yield } \\
\left(\mathrm{kg}^{2} \cdot \mathrm{ha}^{-1}\right)\end{array}$ \\
\hline \multicolumn{4}{|l|}{ Field Trial 1, 2001} \\
\hline Charleston Blackeye & $66.0 \mathrm{~b}^{\mathrm{y}}$ & $14.4 \mathrm{~b}$ & $644 \mathrm{a}$ \\
\hline Green Dixie Blackeye & $69.2 \mathrm{a}$ & $15.2 \mathrm{a}$ & 606 a \\
\hline \multicolumn{4}{|l|}{ Field Trial II, 2002} \\
\hline Charleston Blackeye & $70.5 \mathrm{a}$ & $17.4 \mathrm{~b}$ & 1,409 a \\
\hline Green Dixie Blackeye & $73.5 \mathrm{a}$ & $18.4 \mathrm{a}$ & $1,213 \mathrm{a}$ \\
\hline \multicolumn{4}{|c|}{ Combined analysis of both trials } \\
\hline Charleston Blackeye & $67.3 b^{\mathrm{NS}}$ & $15.3 \mathrm{~b}^{\mathrm{NS}}$ & $862 \mathrm{a}^{\mathrm{N}}$ \\
\hline Green Dixie Blackeye & $70.4 \mathrm{a}$ & $16.1 \mathrm{a}$ & $775 \mathrm{a}$ \\
\hline
\end{tabular}

${ }^{{ }^{2}}$ Spring 2001 and 2002 trials planted on 5 June and 4 June, respectively. Experimental design of each trial was a randomized complete block with 10 replications (2001) or 4 replications (2002).

${ }^{y}$ Mean separation within columns and trials by Student-Newman-Keuls multiple range test, $P \leq 0.05$.

${ }^{\mathrm{N} N}$ Nonsignificant interaction between cultivar and trial. 'Charleston Blackeye' is homozygous for the $R k$ pods are long, nearly straight, and exhibit a in 2001 and 2002 to compare the maturity, seed size, and yield characteristics of 'Charleston Blackeye' and 'Green Dixie Blackeye' (Fery, 2002). The results of these studies (Table 1) indicated that 'Charleston Blackeye', on average, is significantly earlier than 'Green Dixie Blackeye' (67 vs. $70 \mathrm{~d})$, produces significantly smaller seeds (15.3 vs. 16.1 g per 100 dry seeds), and exhibits a similar yield potential (862 vs. $775 \mathrm{~kg} \cdot \mathrm{ha}^{-1}$ ).

'Charleston Blackeye' was evaluated as US-1033 throughout the southern U.S. as an observational entry in the 2000 Regional Southernpea Cooperative Trials and as a replicated entry in the 2001 and 2002 trials. During three years of testing in these trials (total of 22 tests in 6 states), the yield of 'Charleston Blackeye' averaged $104 \%$ of the yield of the blackeye-type control (Arkansas Blackeye No. 1). Canned samples of fresh 'Charleston ( tests conducted in 2000,2001, and 2002 at University of Arkansas (T. Morelock and J. Goff, unpublished data). The average processed grade of canned samples (average of scores 3 years for color of peas, color of liquor, wholeness, texture, flavor, and general appearance: $1=$ poorest, $10=$ best; unacceptable score $<6$ ) was 8.16 for Charleston Blackeye and 8.17 or Arkansas Blackeye No. 1.

The results of many field tests indicate that 'Charleston Blackeye' does not have unusual susceptibility to any major southernpea disease. gene that conditions resistance to the southern root-knot nematode [M. incognita (Kofoid and White) Chitwood], the Javanese root-knot nematode [M. javanica (Treub.) Chitwood], and the northern root-knot nematode [M. hapla Chitwood] (Fery andDukes, 1980). 'Charleston Blackeye' has exhibited a high level of resistance the numbers of galls and egg masses on the roots have always been minimal (Table 2).

'Charleston Blackeye' is recommended for use by home gardeners for production of fresh-shell, blackeye-type peas. 'Charleston Blackeye' is also recommended for trial by market gardeners to produce attractive freshshell stage pods and fresh-shell peas for sale in farmers' markets. The fresh-shell stage yellow color. 
Table 2. Average root-gall index and average egg mass index for 'Charleston Blackeye', 'Arkansas Blackeye No. 1', 'Mississippi Silver', 'Pinkeye Purple Hull-BVR', and 'New Era' plants grown in soil infested with the southern root-knot nematode, Meloidogyne incognita race 3 (2000, 2001, and 2002 Greenhouse experiments). ${ }^{z}$

\begin{tabular}{|c|c|c|}
\hline Cultivar & $\begin{array}{c}\text { Root } \\
\text { gall } \\
\text { index }^{y}\end{array}$ & $\begin{array}{c}\text { Egg } \\
\text { mass } \\
\text { index }^{x}\end{array}$ \\
\hline \multicolumn{3}{|l|}{ Greenhouse Trial 1, 2000} \\
\hline Charleston Blackeye & 1.4 & 1.4 \\
\hline Arkansas Blackeye No. $1^{\mathrm{w}}$ & 4.9 & 4.9 \\
\hline Mississippi Silver ${ }^{v}$ & 1.2 & 1.1 \\
\hline Pinkeye Purple Hull-BVR w & 4.7 & 4.7 \\
\hline New Eraw & 5.0 & 5.0 \\
\hline $\operatorname{LSD}(0.05)$ & 0.5 & 0.4 \\
\hline \multicolumn{3}{|l|}{ Greenhouse Trial II, 2001} \\
\hline Charleston Blackeye & 1.2 & 1.1 \\
\hline Arkansas Blackeye No. $1^{\mathrm{w}}$ & 5.0 & 4.9 \\
\hline Mississippi Silverv & 1.1 & 1.1 \\
\hline Pinkeye Purple Hull-BVR ${ }^{w}$ & 5.0 & 5.0 \\
\hline New Era ${ }^{w}$ & 5.0 & 5.0 \\
\hline $\operatorname{LSD}(0.05)$ & 0.5 & 0.5 \\
\hline \multicolumn{3}{|l|}{ Greenhouse Trial III, 2002} \\
\hline Charleston Blackeye & 1.3 & 1.2 \\
\hline Arkansas Blackeye No. $1^{\mathrm{w}}$ & 5.0 & 5.0 \\
\hline Mississippi Silverv & 2.1 & 2.1 \\
\hline Pinkeye Purple Hull-BVR ${ }^{w}$ & 4.7 & 4.7 \\
\hline New Era ${ }^{w}$ & 5.0 & 5.0 \\
\hline $\operatorname{LSD}(0.05)$ & 0.5 & 0.5 \\
\hline
\end{tabular}

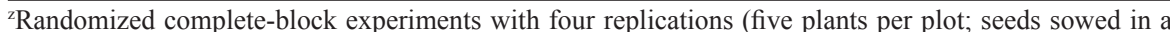
steam-pasteurized mixture of soil and sand on 23 Aug. 2000, 25 June 2001, and 5 Aug. 2002, respectively; each seed inoculated with $3000 \mathrm{M}$. incognita race 3 eggs at sowing (2000 and 2002) or shortly after plant emergence (2001); roots of all plants evaluated for galling and egg masses on 20 Oct. 2000, 16 Aug. 2001, and 23 Sept. 2002, respectively.

${ }^{\mathrm{y}}$ Rated on a scale of 1 to $5: 1=$ no galls; 2 = light galling, $1 \%$ to $25 \%$ of root system galled; $3=$ moderate galling, $26 \%$ to $50 \%$ of root system galled; $4=$ heavy galling, $51 \%$ to $80 \%$ of root system galled; and $5=$ severe galling, $81 \%$ to $100 \%$ of root system galled.

${ }^{x}$ Rated on a scale of 1 to $5: 1=$ no egg masses evident, $2=$ scattered egg masses covering $1 \%$ to $25 \%$ of root system, $3=$ moderate number of egg masses covering $26 \%$ to $50 \%$ of root system, $4=$ many egg masses covering $51 \%$ to $80 \%$ of root system, and $5=$ extremely large number of egg masses covering $81 \%$ to $100 \%$ of root system.

wSusceptible control.

vesistant control.

\section{Availability}

Breeder's seed of 'Charleston Blackeye' has been released to seed producers. Small samples of 'Charleston Blackeye' breeder's seed are available from the senior author for distribution to interested research personnel. Genetic material of this release will be deposited in the National Plant Germplasm System where it will be available for research purposes, including development and commercialization of new cultivars. It is requested that appropriate recognition of source be given when this germplasm contributes to research or development of a new breeding line or cultivar.

\section{Literature Cited}

Fery, R.L. 2002. 'Green Dixie Blackeye', a green cotyledon, blackeye-type southernpea. HortScience 37:233-234.

Fery, R.L. and P.D. Dukes. 1980. Inheritance of root-knot nematode resistance in cowpea [Vigna unguiculata (L.) Walp.]. J. Amer. Soc. Hort. Sci 105:671-674.

Fery, R.L. and P.D. Dukes. 1993. 'Bettergro Blackeye’ southernpea. HortScience 28:62-63. 